\begin{tabular}{|c|c|c|}
\hline $\begin{array}{c}\text { Military Technical College } \\
\text { Cairo, Egypt }\end{array}$ & $\begin{array}{c}12^{\text {th }} \text { International Conference } \\
\text { on Applied Mechanics and } \\
\text { Mechanical Engineering (AMME) }\end{array}$ \\
\hline
\end{tabular}

\title{
SIDE-STICK CONTROL OF POWER RACK AND PINION STEERING SYSTEM
}

\author{
Asfoor $^{*}$ M. Sh., Ebraheem M. H., El-Haddad ${ }^{* *}$ M. A.
}

\section{ABSTRACT}

Nowadays, a great development is occurring in the automotive systems due to introduction of electronics, which act as an integrated part with the mechanical system. The result of this integration appeared as an improvement in all phases of automotive functions as: driving performance, fuel efficiency, exhaust purification, safety \& comfort.

The objective of this research is to control electronically the steering in a vehicle with power steering system using a side-stick. To achieve this goal an electronically controlled module is proposed, realized and implemented on a steering system. This module is operated using a side stick and the necessary sensors and actuators which replaces the conventional steering wheel.

An embedded controller is used as a control unit and the required interfacing circuits are designed and implemented. For investigation of the control system, a mathematical model is prepared. Finally the overall test rig is built-up and the control system testing showed a great benefit in modifying a conventional steering system to be electronically controlled. The simulation results agree to a great extent with the real test results.

\section{KEY WORDS}

Rack \& Pinion, Side-Stick Steering, Embedded controller, Electronic control.

\footnotetext{
* Egyptian Armed Forces.

* Egyptian Armed Forces.

${ }^{* *}$ Higher Institute of Technology- $10^{\text {th }}$ of Ramadan.
} 


\section{NOMENCLATURE}

$A_{p} \quad$ Piston cross section area $\left[\mathrm{m}^{2}\right]$.

$A_{s} \quad$ Spool cross section area $\left[\mathrm{m}^{2}\right]$.

$B \quad$ Damping ratio of the mechanical components of the dc motor in $[\mathrm{N} . \mathrm{m} / \mathrm{s}]$.

$C_{S} \quad$ Damping factor acting on spool [N.s/m].

$(C A)_{i}$ Product of coefficient of discharge and area of valve opening.

$F_{L} \quad$ Load force exerted on the rack \& pinion assembly $[\mathrm{N}]$.

$F_{f s} \quad$ Friction force acting on spool $[\mathrm{N}]$.

$F_{l s} \quad$ Flow force acting on spool [N].

$i_{a} \quad$ DC motor armature current. [A]

$\mathrm{J}_{1} \quad$ Moment of inertia of the motor in $\left[\mathrm{kg} \cdot \mathrm{m}^{2}\right]$.

$\mathrm{J}_{2} \quad$ Mechanical subsystem moment of inertia [kg. $\left.\mathrm{m}^{2}\right]$.

$K_{b} \quad$ DC motor back emf damping constant in [N.m/s].

$K_{1} \quad$ Torsion bar stiffness [N.cm/rad].

$K_{f} \quad$ Bulk modulus [Pa].

$k_{s} \quad$ Return spring stiffness [N/m].

$K_{T} \quad$ Dc motor's torque constant in [Nm/V].

L DC motor electric inductance.

$m$ Lumped mass of mechanical system components $[\mathrm{Kg}]$.

$m_{s}$ Spool mass [kg].

$\triangle P$ The generated differential pressure across the cylinder [Pa].

$Q_{t} \quad$ Pump discharge flow rate $\left[\mathrm{m}^{3} / \mathrm{s}\right]$.

$Q_{f r}$ Flow rate into return port $\left[\mathrm{m}^{3} / \mathrm{s}\right]$.

$Q_{i} \quad$ Flow rate through orifice $\left[\mathrm{m}^{3} / \mathrm{s}\right]$.

$Q_{m}$ Flow rate through metering orifice $\left[\mathrm{m}^{3} / \mathrm{s}\right.$ ]

$R \quad$ DC motor electric resistance in $[\Omega]$.

$r$ Pinion radius [m].

$V_{p t}$ Volume of supply port in pump $\left[\mathrm{m}^{3}\right]$.

$x$ Rack displacement [m].

$x_{S} \quad$ Spool displacement [m].

$x_{s i} \quad$ Initial displacement of the spool [m].

$\theta_{1} \quad$ Rotational displacement of the torsion bar [rad].

$\rho \quad$ Density of fluid $\left[\mathrm{kg} / \mathrm{m}^{3}\right]$. 


\section{INTRODUCTION}

The replacement of mechanical systems with electronic controlled systems is a growing trend in the automotive industry. A control system is a collection of components working together under the direction of some machine intelligence. In recent decades, a large amount of research and design work has been conducted in the areas of robotic vehicles and vehicle control systems. Most of the current vehicle electronic control systems are now being enhanced and expanded, In order to provide a high degree of maneuverability and traction. The handling characteristics of road vehicles have been greatly improved in the past twenty years through the use of electronic devices. Recently, integrated chassis control techniques have been proposed for improved handling and safety.

Elhaddad [1] gives a proposal for building up a control module to be mounted on any conventional vehicle to change it to a remote controlled one. The operation of the control module is explained and different control programs' flow charts were given.

TNO Automotive has developed a side-stick system using an optimized relationship between side-stick forces, displacement and vehicle response, based on the best possible feedback. Alternative steering concepts like side-stick steering in combination with steer-by-wire technology offer possibilities to combine functionalities like steering, accelerating and braking in one interface. [2]

The most prominent innovations fitted in the F 200 developed by DaimlerChrysler on October 2004 included an imaginative new driving control system which allowed the driver to control all vehicle movements by means of side sticks positioned in the door trim panels and in the centre console of the vehicle. Moving the side sticks to the left or right steered the vehicle, pushing the levers forward accelerated, pulling it back applied the brakes. [3]

Sanket Amberkas et. Al. of Delphi Automotive systems introduced recent advances in dependable embedded system technology showing a simple design for steer-bywire system, the system can be subdivided into three major parts: a controller, a steering wheel subsystem, and a road wheel subsystem. [4]

In this paper a power rack and pinion steering mechanism is modified to be controlled by the driver using a side-stick. The system description is explained indicating the principle of this modification. To evaluate the system parameter, a test rig is built-up and a mathematical modeling and simulation using MATLAB ${ }^{\circledR}$ are used. The system validation is proved by comparing the test results with the simulation results.

\section{SYSTEM DESCRIPTION}

The system is designed to suit the actions of an average driver in case of driving a conventional vehicle. The steering wheel and the steering column are eliminated and 
replaced by a side-stick. The proposed control system algorithm takes the decisions based on side-stick input and operates the actuator that drives the mechanical linkage of the steering system according to the information based on vehicle characteristic data, initial conditions and input steering signal. The control system determines the appropriate steering angle where it executes the required output as a closed loop system. Fig. 1 shows a simple block diagram of the control system.

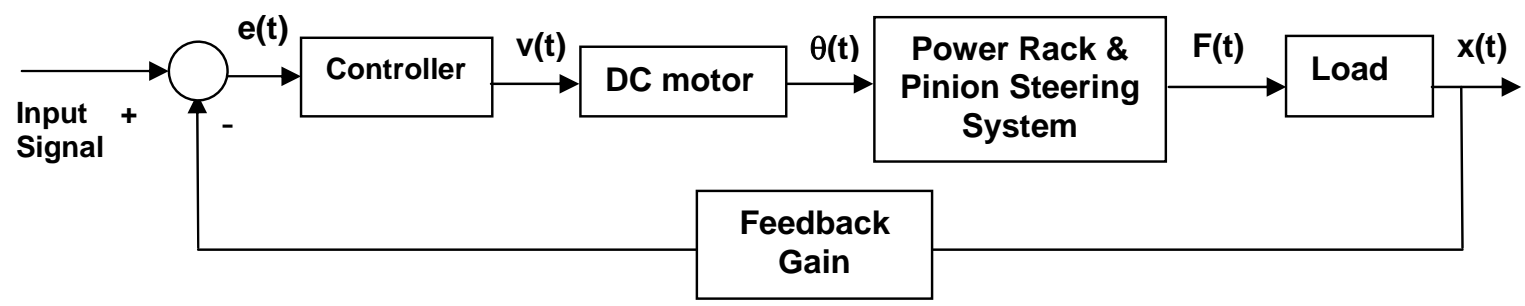

Fig.1 Control system block diagram

Where:
$\mathrm{e}(\mathrm{t}) \ldots \ldots \ldots$ is the error signal
$\mathrm{v}(\mathrm{t}) \ldots \ldots \ldots \mathrm{dc}$ motor actuating signal
$F(t) \ldots \ldots \ldots$ steering actuating force
$\mathrm{x}(\mathrm{t}) \ldots \ldots \ldots$ rack displacement
$\theta(\mathrm{t}) \ldots \ldots \ldots$ angular displacement of motor shaft

In this controlled system there are several input signals, the first is the steering angle given by the driver, the second is the rack displacement signal, which is fed as a feedback using a displacement sensor, the delivery and return pressure lines signals and the full right and full left rack position signals. All of these signals are fed to the data acquisition card (DAC) in the controller. Based on the sensors' data and the control algorithm, the embedded controller calculates the required outputs which are interfaced using interfacing circuits that output actuator command signals in realtime.

\section{TEST RIG SETUP}

A power rack and pinion steering mechanism is mounted on a frame with applied simulated load. Fig. 2 shows the mounting and fixation of the applied load. Induction motor drives the hydraulic pump by means of a belt to supply the hydraulic circuit with oil flow is fixed as shown in fig. 3. 


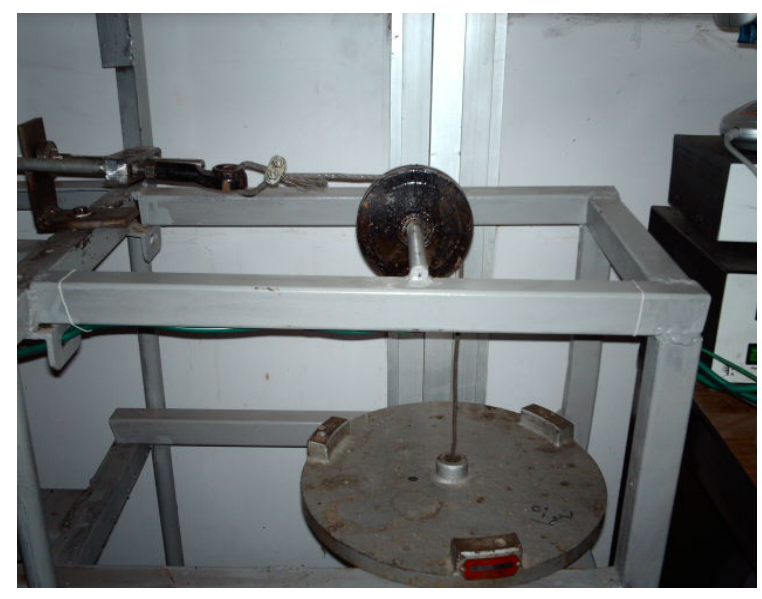

Fig.2 Mounting and fixation of the applied load

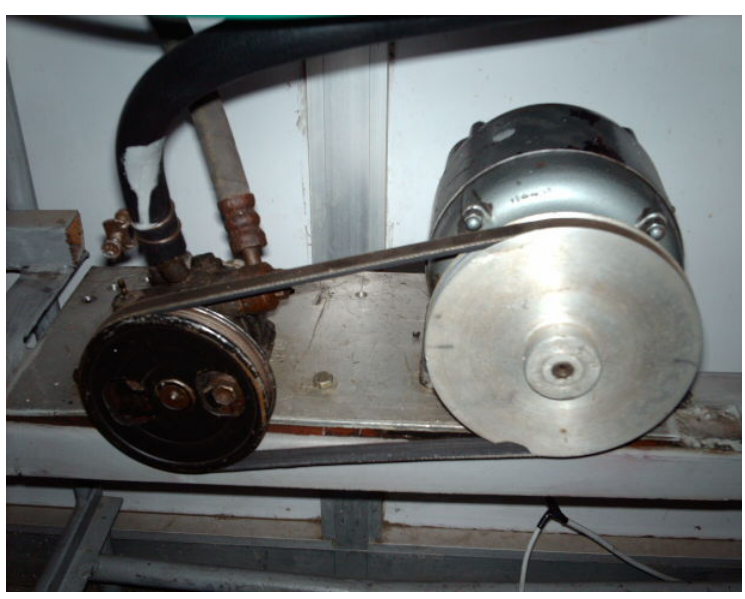

Fig.3 The induction motor driving power steering pump

The needed sensory elements are added, where a displacement sensor having a resistance of $77 \Omega$, a working length of $13 \mathrm{~cm}$ and applied voltage of $5 \mathrm{~V}$ is adapted to the tie rod as shown in fig.4. The slider of this sensor delivers its output voltage to an analogue input channel in the used DAC indicating rack displacement.

Two pressure sensors are mounted and adapted to the pump and return pressure lines using a threaded $\mathrm{T}$ shaped connector and a high pressure hoses as shown in fig.5. Again, the voltages of the pressure sensors are fed to the DAC where the differential pressure is multiplied by the piston cross sectional area giving the applied assisting force.

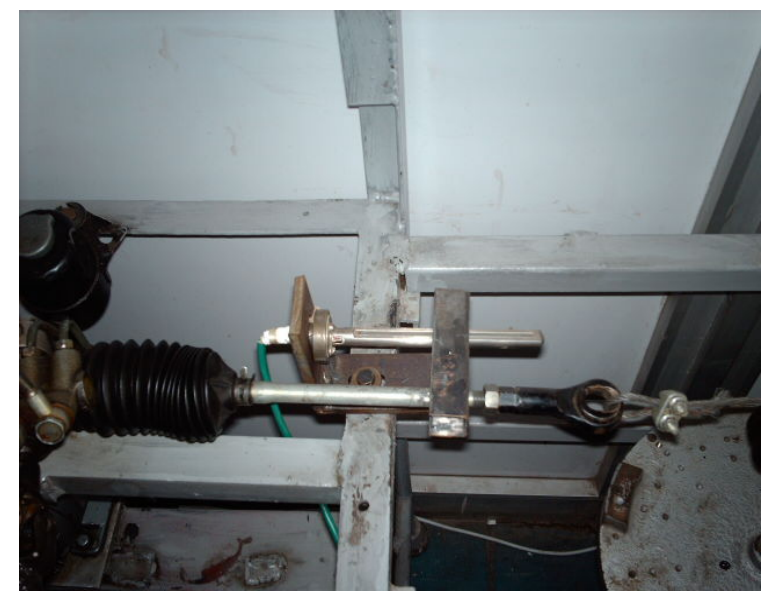

Fig.4 Adaptation of displacement sensor to the rack (Tie rod).

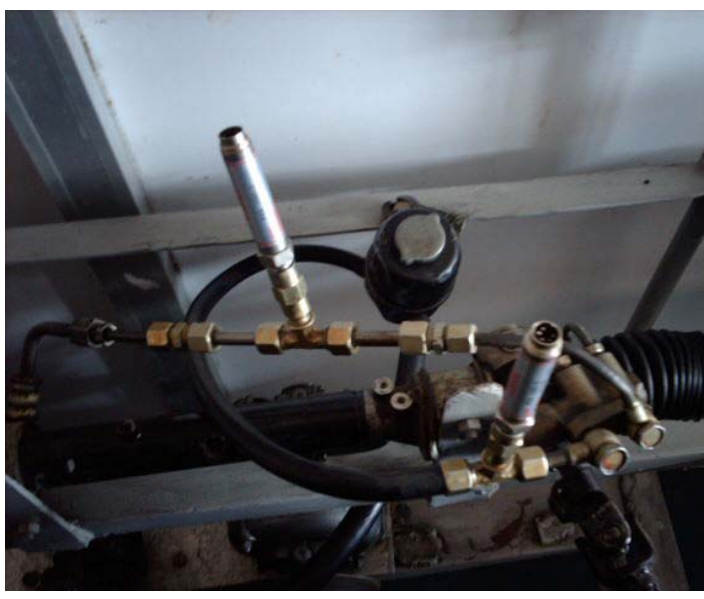

Fig.5 Mounting \& adaptation of the used pressure sensors

The driving DC motor is selected and adapted to the driving shaft as shown in fig. 6 which is considered as main actuator for driving the hydraulic control valve of power 
steering in both right and left directions. Interfacing circuits are designed and implemented in a control box as shown in fig. 7 .

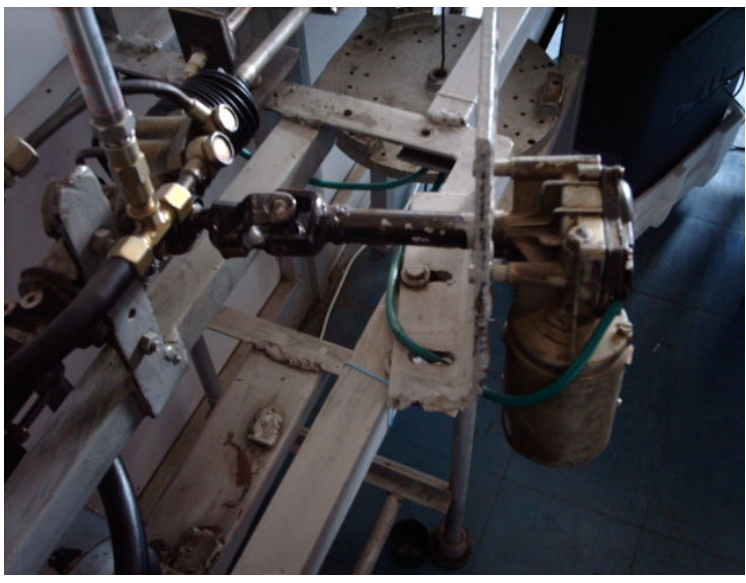

Fig.6 Mounting \& adaptation of the used DC motor

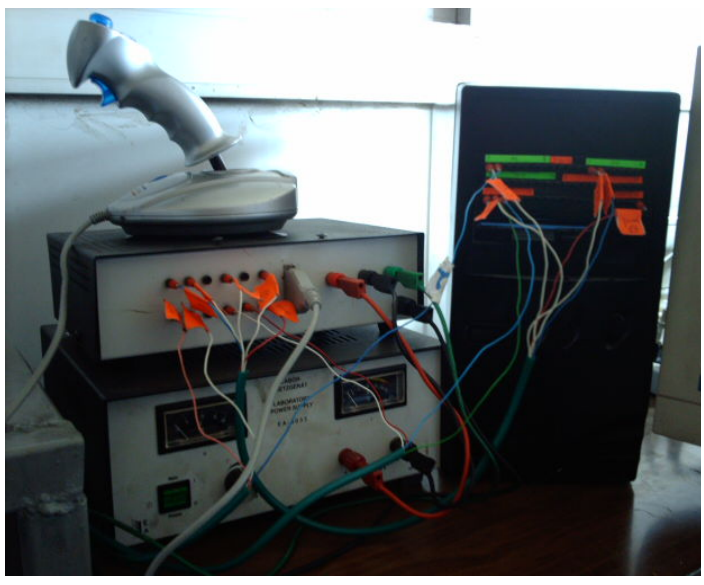

Fig.7 Controller and Interfacing module

\section{TESTING PROCEDURE}

The dynamic response of steering system of a vehicle is often tested with a step steer input. Methods for the calculation and evaluation of an ideal response, as used in system theory or control techniques, can not be used with a real car, for a step input at the steering wheel is not possible in practice. But, in this system a step steer input is applied to the motor.

The angle at the steering wheel is not the decisive factor for the driving behavior, but the steer angle at the wheels, which can differ from the steering wheel angle because of elasticities and friction influences indicating the steering behavior. For these reasons the steering response to step steer input will be compared with the simulation results. Also the rack displacement, cylinder and pump output pressures are measured.

\section{SYSTEM MODELLING}

The most important requirement in modelling a system is the complete understanding of the performance specifications, physical and operational characteristics of each component in the system. Lot effort had been made to model various steering systems [5-8] but, most of the research had been conducted on modelling components or the static characteristics of the steering system.

The power steering system considered in this research can be subdivided into two subsystems: the mechanical subsystem and the hydraulic subsystem in addition to the dc motor subsystem as a main actuator. The mechanical subsystem components are: the torsion bar, the rack and the pinion steering gearbox. The operation of 
steering system is as follows: The driver generates the input torque, $T_{d}$, at the steering wheel. The torque is transmitted through the upper steering column to the torsion bar that twists with an angle $\theta$. An elastic torque, proportional to the twist angle of the bar $\left(\theta=\theta_{1}-\theta_{2}\right)$, opposes the input torque. The torsion bar transmits the input torque to the pinion. The pinion transforms the input torque into a force on the rack. This force adds to the force created by the hydraulic system (the assist force) to overcome the resistant force from the wheels $F_{R}$.

The hydraulic subsystem components are: the pump, the rotary valve and the hydraulic cylinder and the piston. The pump continuously supplies oil flow to the rotary valve. This valve consists of an inner spool, and outer sleeve and a torsion bar (common to the mechanical subsystem). The spool rotates directly with the rotation of the steering wheel (angle $\theta_{1}$ ). The valve sleeve, torsion bar cap and pinion are pinned together. Longitudinal slots in the interior surface of the sleeve and the exterior surface of the spool produce the metering orifices of the valve. In the absence of a torque input, the torsion bar is not twisted $\left(\theta_{1}=\theta_{2}\right)$ and the metering orifices areas are equal on both sides of the valve (corresponding to the left or right side of the cylinder). No differential pressure is generated across the cylinder. If the system is excited by a torque input, the torsion bar twists with an angle $\left(\theta=\theta_{1}-\theta_{2}\right)$, creating a displacement between the spool and the sleeve of the valve. This displacement corresponds to a change in the area of the metering orifices. Therefore, a differential pressure is created across the cylinder. The pressure is transformed into force on the rack by the piston. This force represents the power steering assist.

As shown here, there are a lot of parameters included in the power steering model. So MATLAB® SIMULINK [9] program was used to model the equations governing the operation of the system. The overall simulink model is shown in fig. 8 , where most of the power steering components were considered.

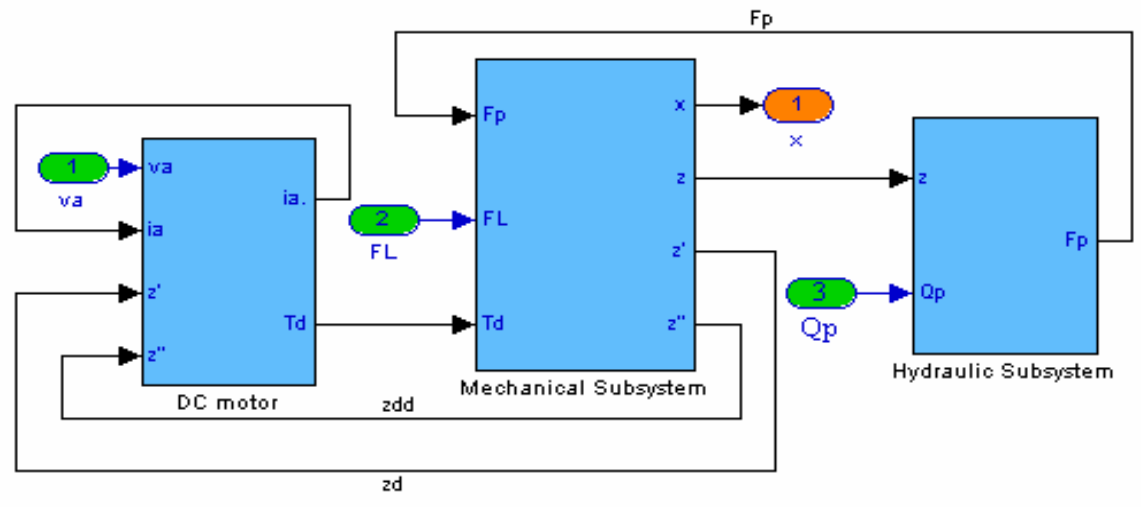

Fig.8 Steering system simulink model

\subsection{Motor Subsystem Modeling}

The transfer function of the dc motor can be written from the electric circuit of its armature and the free body diagram of its rotor as shown in fig.9. 
The resulting system electrical equation of motion is given by equation (1), and the motor mechanical equation of motion is given by equation (2). Both equations were used in the dc motor subsystem simulink model as shown in fig. 10. [10]

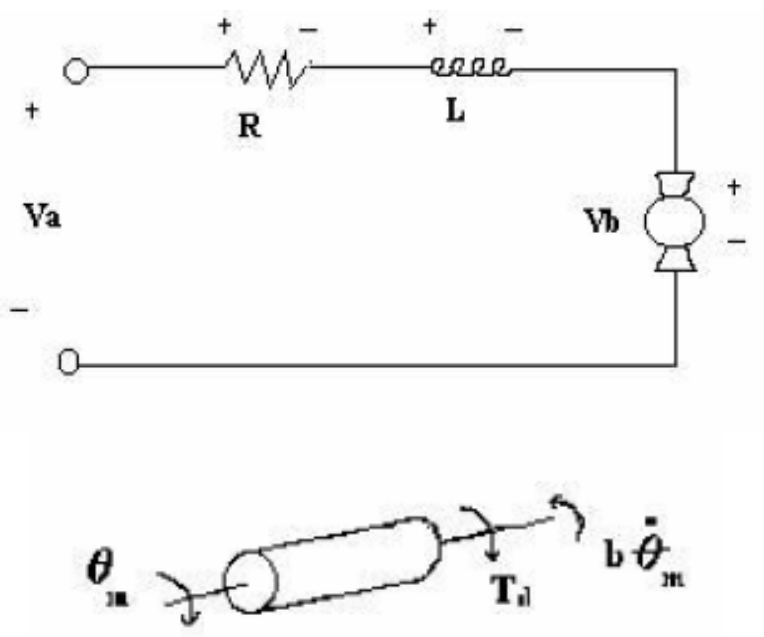

Fig.9 Circuit diagram of motor armature and free body diagram of its rotor

$$
\begin{gathered}
L \frac{d i_{a}}{d t}+R i_{a}+K_{b} \theta^{\bullet}=v_{a} \\
J_{1} \theta^{\bullet \bullet}+b \theta^{\bullet}=k_{T} i_{a}
\end{gathered}
$$

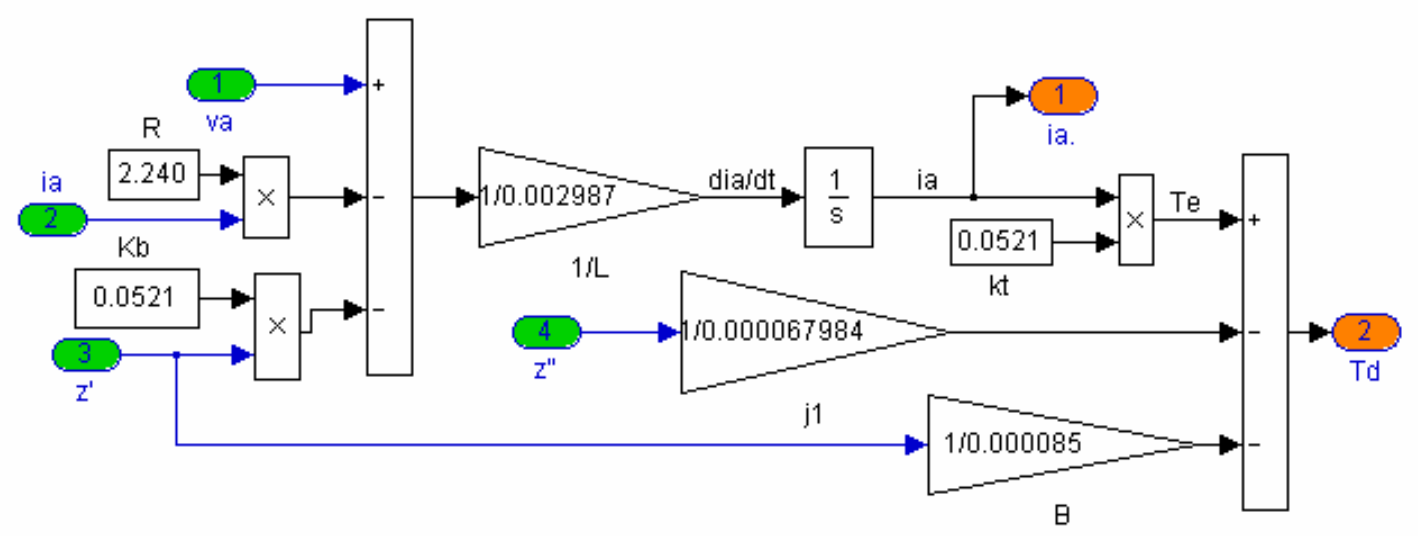

Fig.10 DC motor subsystem simulink model 


\subsection{Mechanical Subsystem Modelling}

The inputs to this system are the torque generated by the driver and the assisting force of the piston (output of the hydraulic system). Since we present a model of the power steering system, details of the tire dynamics are neglected. The outputs of the mechanical subsystem are the displacement of the rack, $X$, and the rotational displacement of the steering column $\theta_{1}$. The equations of motion for the torsion bar, pinion and rack can be derived form the simplified model of steering rack and pinion system shown in Fig. 11. Mechanical subsystem simulink model is shown in fig. 12.

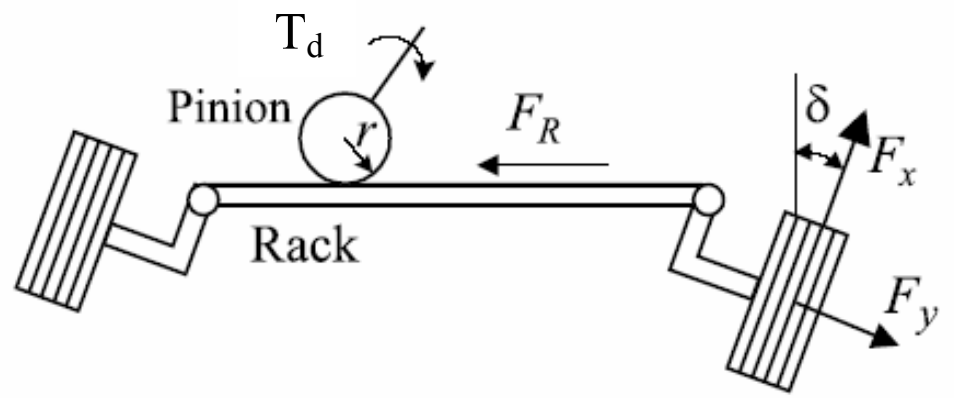

Fig.11 Simplified model of rack and pinion steering system.

$$
\begin{gathered}
T_{d}=J_{2} \theta_{1}^{\bullet \bullet}+b \theta_{1}^{\bullet}+K_{1}\left(\theta_{1}-\frac{x}{r}\right) \\
m x^{\bullet \bullet}=\frac{K_{1}}{r}\left(\theta_{1}-\frac{x}{r}\right)+\Delta P \cdot A_{p}-F_{L}
\end{gathered}
$$

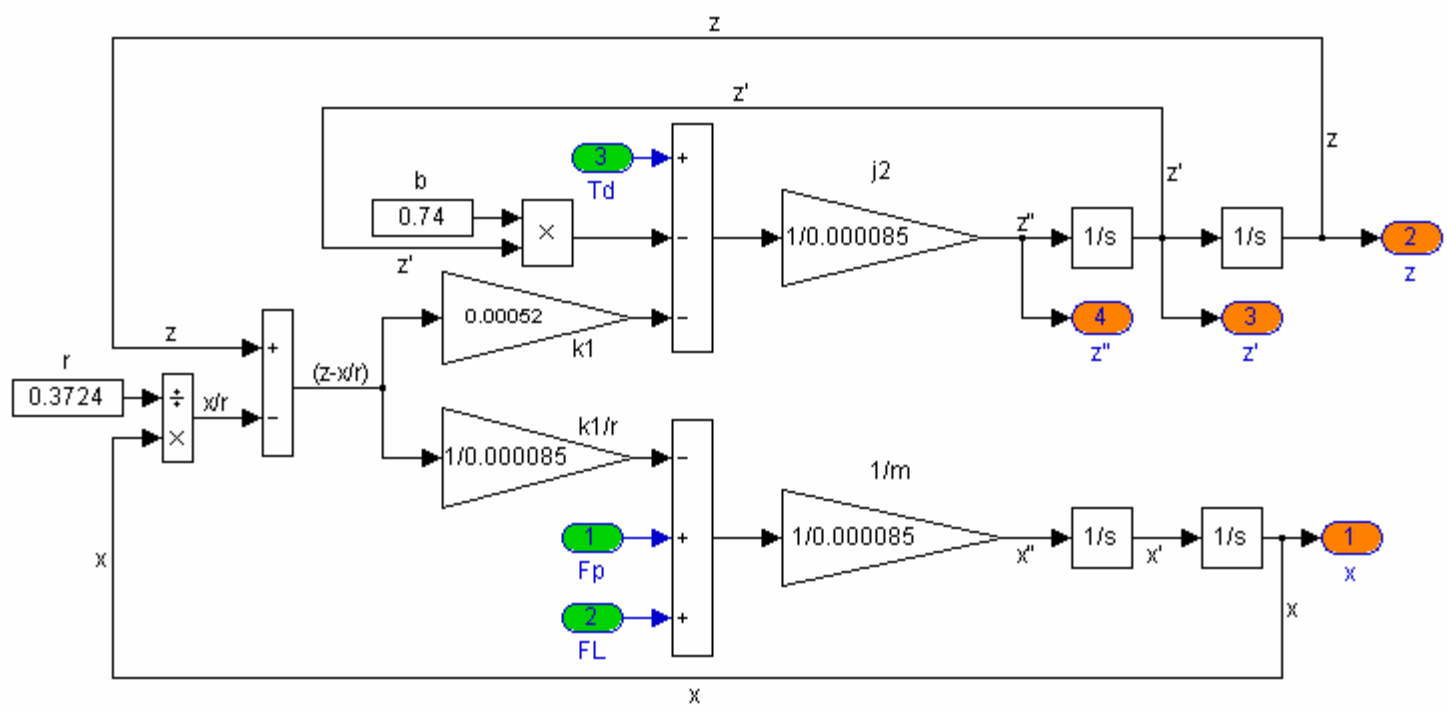

Fig.12 Mechanical subsystem simulink model 


\subsection{Hydraulic Subsystem Modelling}

The inputs to the system are: the flow rate of fluid supplied by the pump, the displacement of the rack and the rotational displacement of the steering column. The output of the system is the differential pressure across the cylinder as shown in the schematic drawing of fig.13. The hydraulic subsystem model is shown in fig. 14. [11]

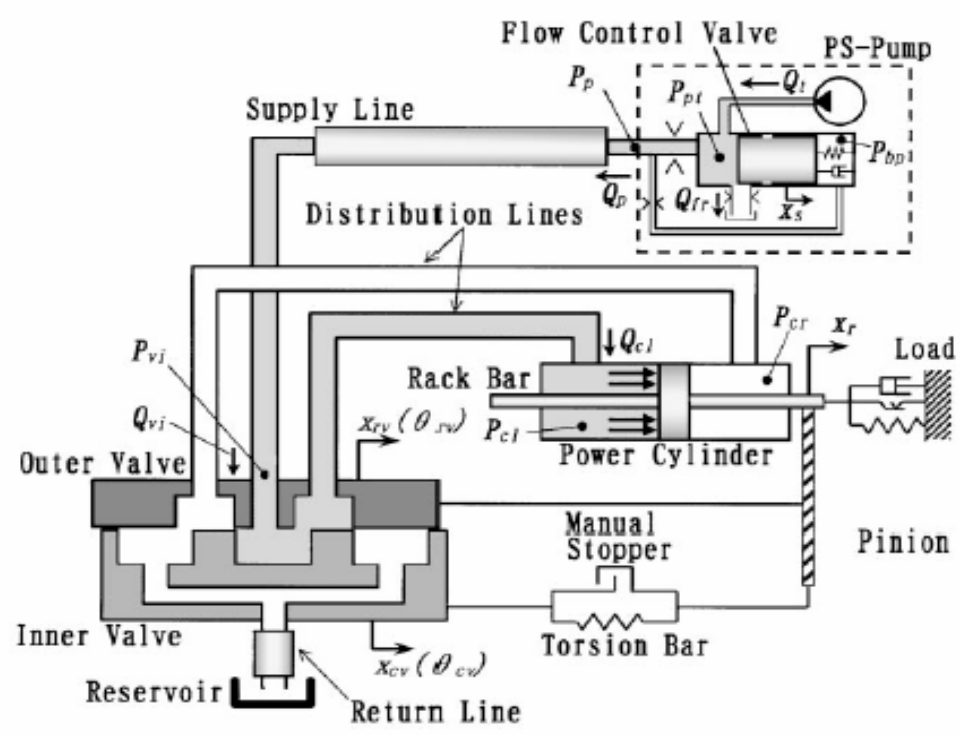

Fig.13 Schematic diagram of the hydraulic system.

The pump is modelled by a series connection of a flow source with flow control valve. The spool behaviour of the flow control valve and pressure at the chamber $\left(P_{p t}\right)$ are determined as follows:

$$
\begin{gathered}
m_{s} \cdot x_{s}^{\bullet \bullet}=\Delta P_{s} \cdot A_{s}-k_{s} \cdot\left(x_{s}+X_{s i}\right)-C_{s} \cdot x_{s}^{\bullet}-F_{f s}-F_{l s} \\
\frac{d P_{p t}}{d t}=\frac{K_{f}}{V_{p t}+x_{s} \cdot A_{s}} \cdot\left(Q_{t}-Q_{m}-Q_{f r}-A_{s} \cdot x_{s}^{\bullet}\right)
\end{gathered}
$$

The control valve is modeled by four variable orifices as follows:

$$
Q_{i}=(C A)_{i} \cdot \sqrt{\frac{2}{\rho} \Delta P_{i}} \quad(i=1-4)
$$




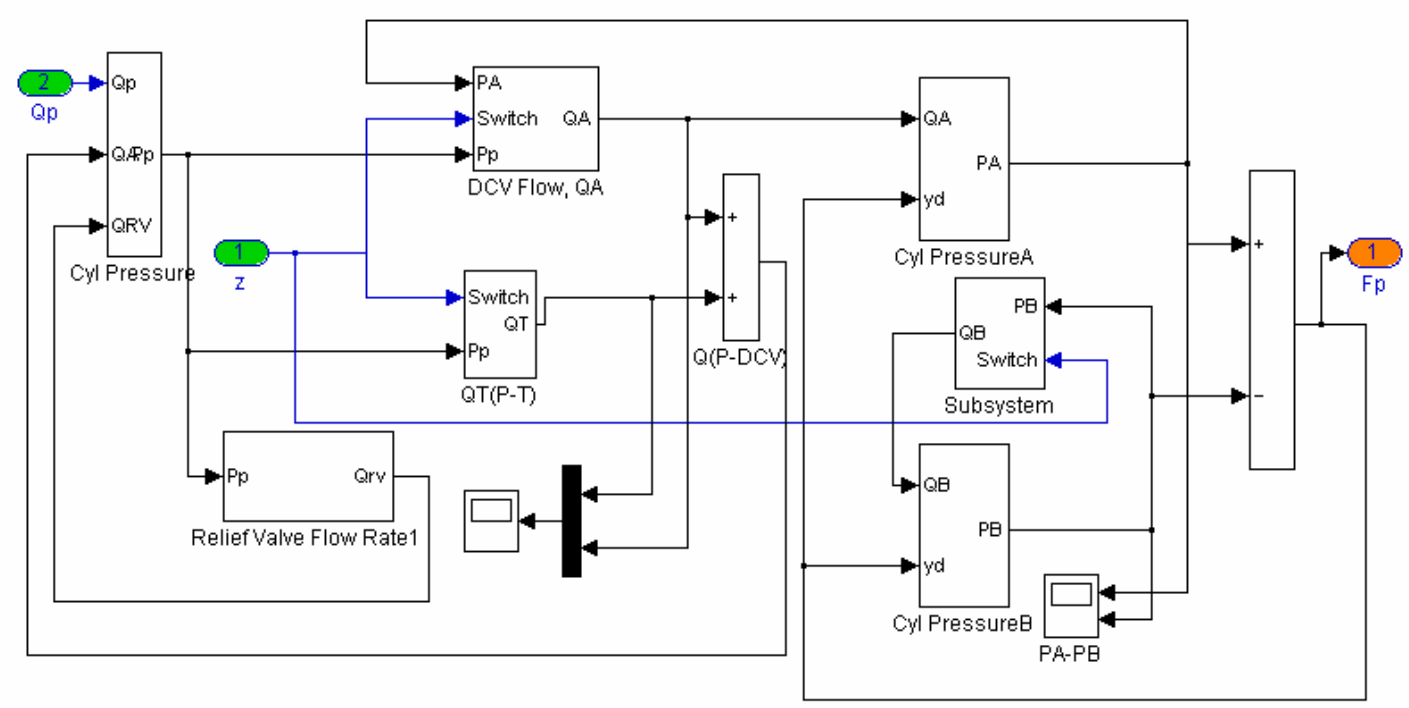

Fig.14 Hydraulic subsystem simulink model

\section{SYSTEM VALIDATION}

The validation procedure consists of comparing the output of the model and the output of the real system under the same input. Several inputs were used in order to analyze the entire spectrum of the output pressure and rack displacement. Fig. 15-18 shows the comparison between measured and simulated results for representative values of the system.

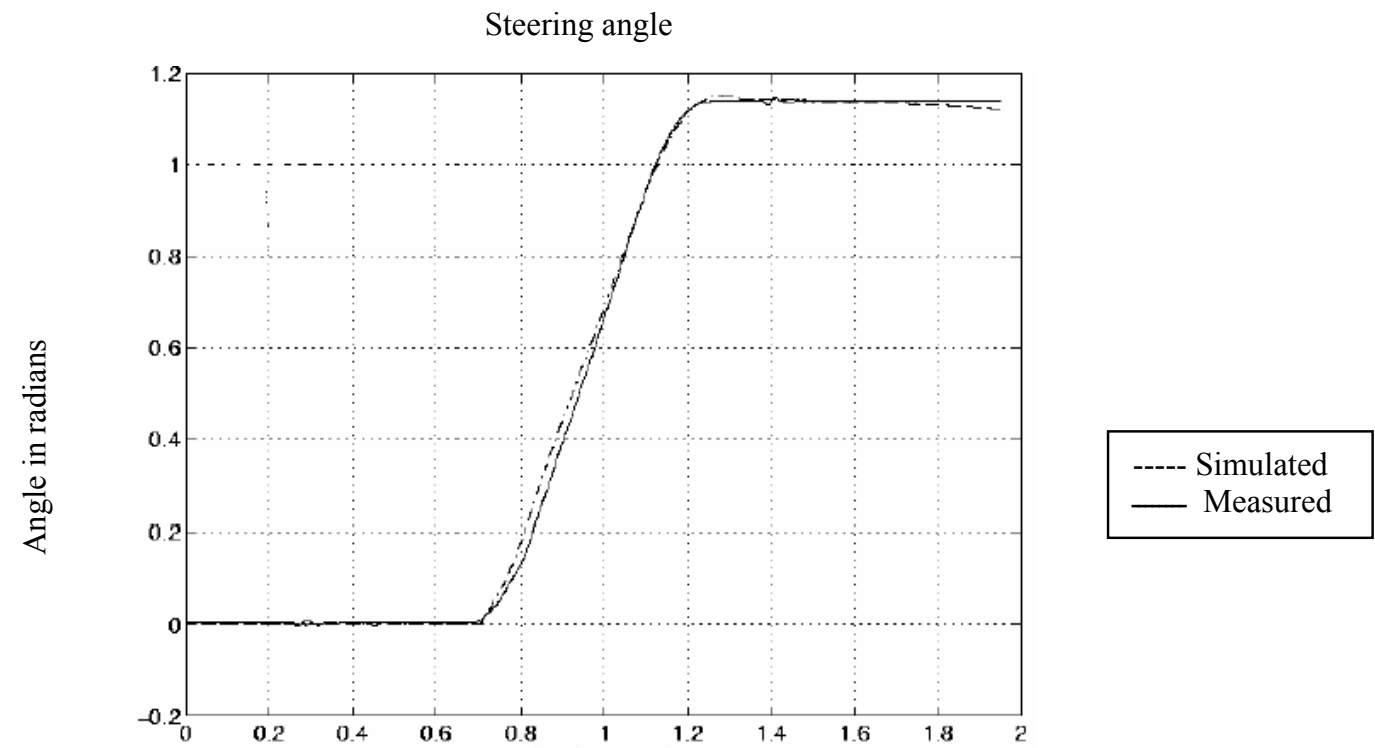

Fig.15 Model validation for the steering angle 


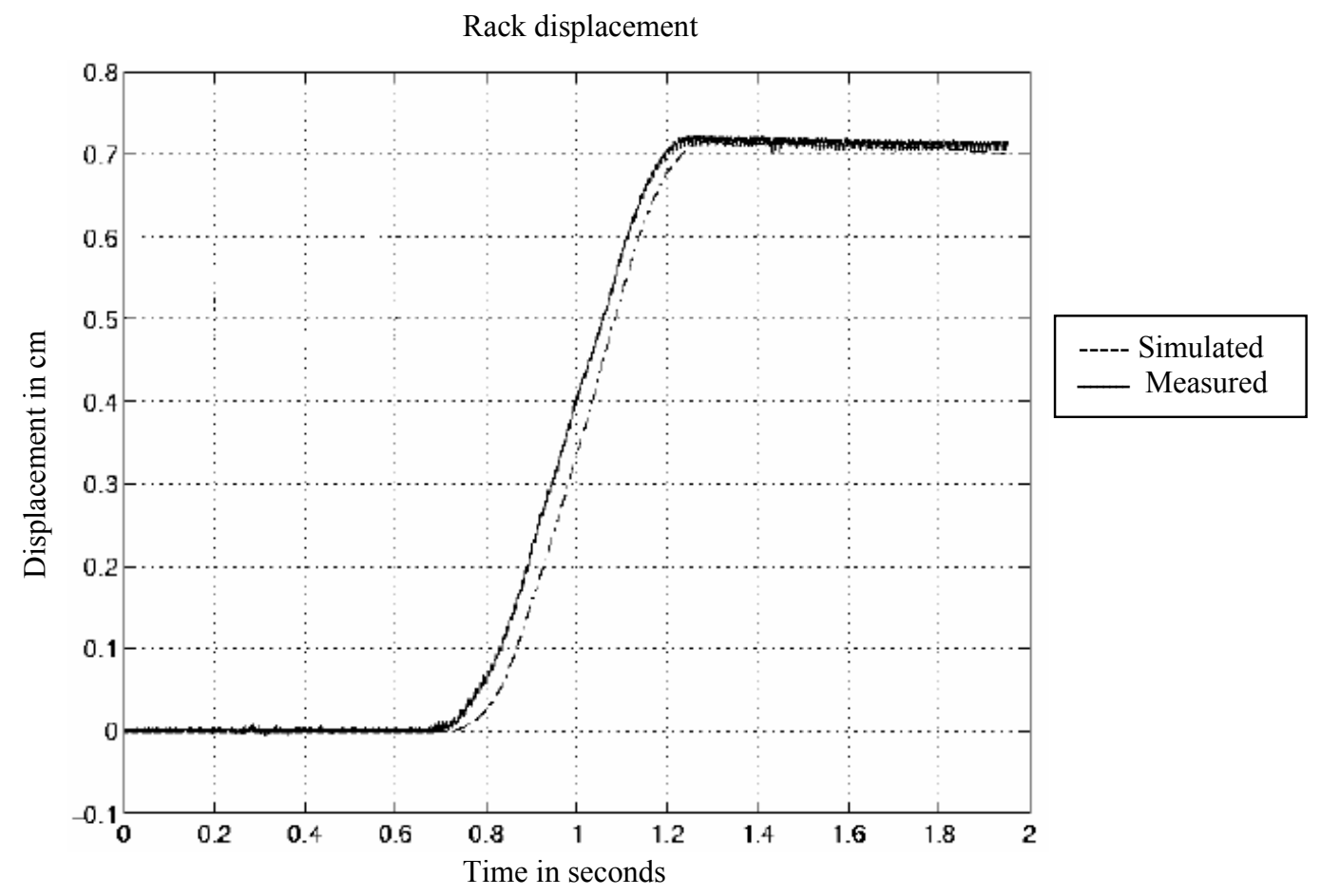

Fig.16 Model validation for the rack displacement

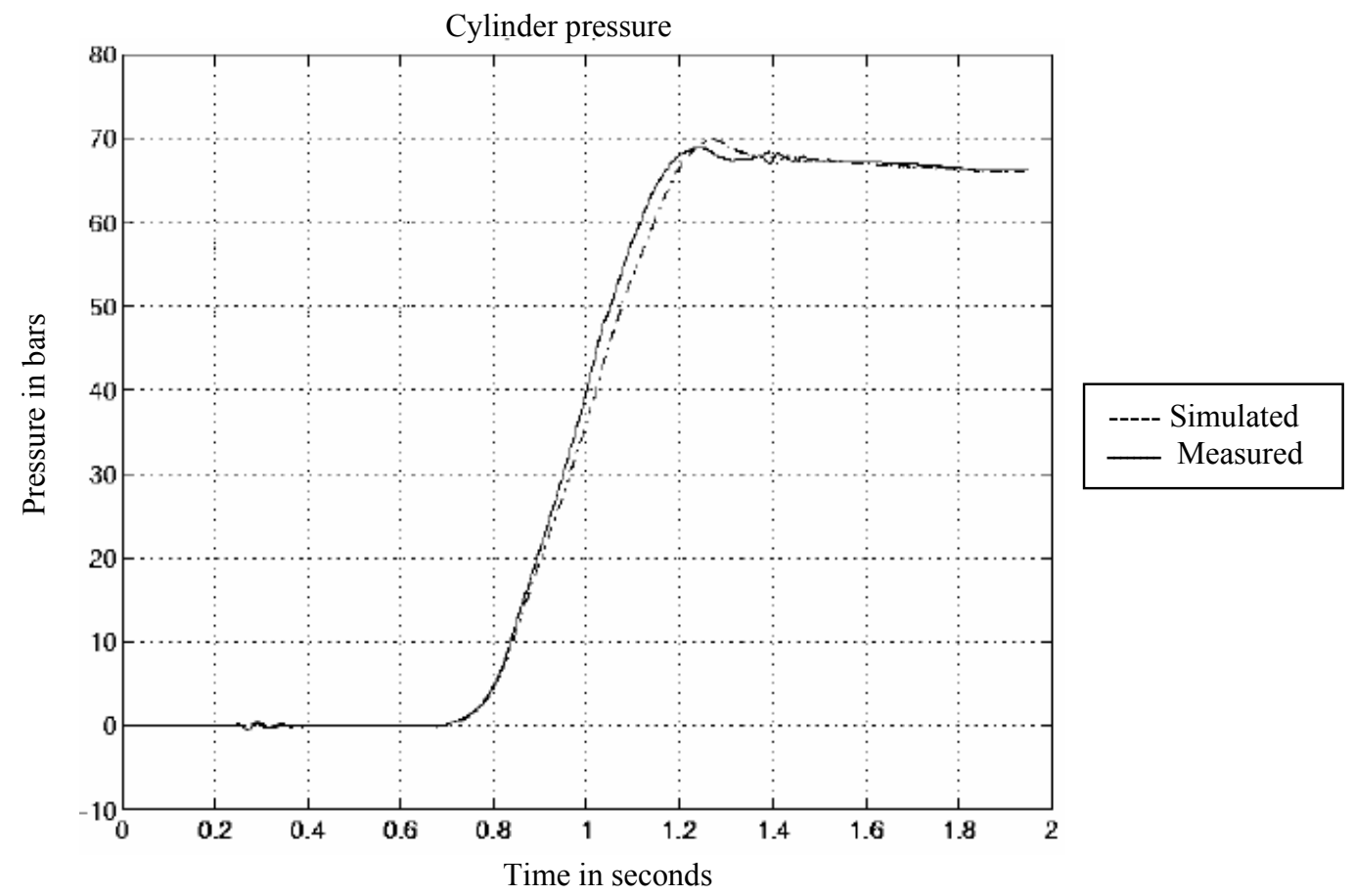

Fig.17 Model validation for the cylinder pressure 


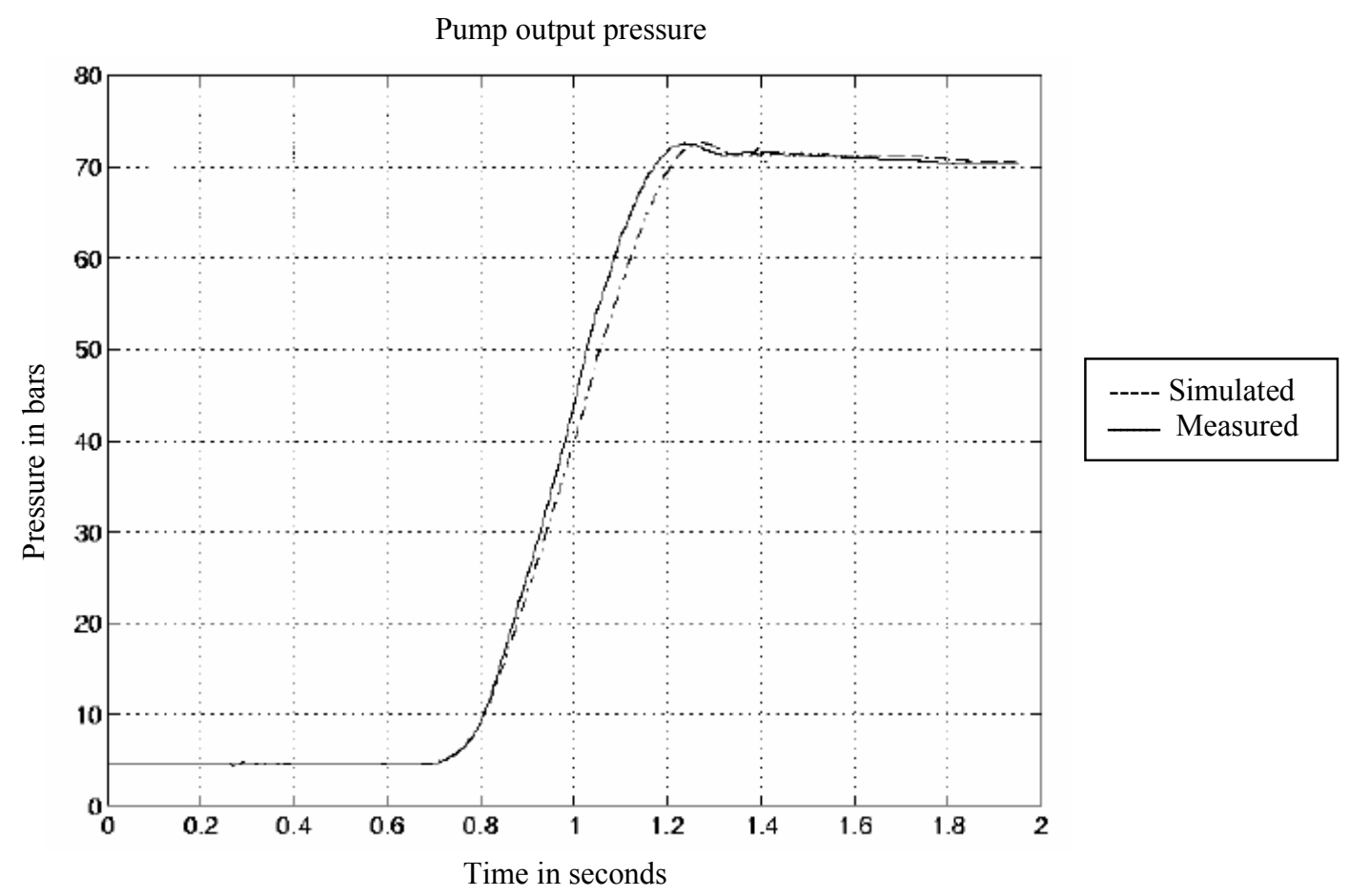

Fig.18 Model validation for the pump pressure

\section{CONCLUSIONS}

The research outlined in this paper has demonstrated the feasibility of modifying a conventional power steering system to be electronically controlled. Such a system is not only feasible but practical, due to the availability of low cost microprocessor technology.

A dynamic model of a power steering system is developed. In which the system is divided into two subsystems: mechanical and hydraulic to facilitate system simulation. The model can be used for performance evaluation and can be easily adapted to fit in a larger vehicle handling model. It can also be used for the design of other power steering systems, where it allows the designer to test changes in dynamic conditions. Other variations, such as pinion radius, stiffness of the torsion bar or piston area can be made as well, and the results tested in the same manner. The simulation results agree to a great extent with the real test results. 


\section{REFERENCES}

[1] Mohamed Aly Elhaddad, Asc.Prof., 10th of Ramadan HTI - 6 Oct. Branch; "Proposal of Remote Driven Ground Vehicle"; Proceedings of the 9th Int. AMME Conference, 16 - 18 May 2000.

[2] www.TNOAutomotive.com

[3] www.DaimlerChrysler.com

[4] Sanket Amberkar, Barbara J. Czerny, Joseph D'Ambrosio, and Brian Murray; Delphi Automotive Systems; "A System-safety process for by-wire automotive systems", Holland Rd., Saginaw, MI.

[5] Tom Wong, Delphi Saginaw Steering Systems; "Hydraulic Power Steering System Design and Optimization Simulation"; SAE 2001-01-0479.

[6] Ji-Hoon Kim, Jae-Bok Song, Department of Mechanical Engineering, Korea University; "Control logic for an electric power steering system using assist motor"; Mechatronics 12 (2002) 447-459.

[7] V D Mills, Michelin Americas Research \& Development Corporation, Greenville, South Carolina, USA and J R Wagner, Department of Mechanical Engineering, Clemson University, Clemson, South Carolina, USA; " Behavioural modelling and analysis of hybrid vehicle steering systems"; D11802 @ IMechE 2003.

[8] S C Yun, N G Cho and C S Han, Department of Mechanical Engineering, Hanyang University, Kyonggi Do, Korea; " A simulation study of the control algorithm for a ball screw type motor-driven power steering system"; D02700 (c) IMechE 2002.

[9] www.mathworks.com

[10] Donald Anderson Gardner; "Experimental Testing of a Decentralized Model Reference Adaptive Controller for a Mobile Robot"; M.Sc. in mechanical engineering, Faculty of the Virginia Polytechnic Institute and State University, July 2001

[11] Shinji Nishimura, Automotive Component Planning Div., Toyoda Machine Works, Ltd., Japan, Tsugiharu Matsunaga, Fluid Dynamics \& Tribology Lab., Toyota Central R\&D Labs., Inc., Japan; "Analysis of response lag in hydraulic power steering system"; JSAE Review 21 (2000) p 41-46, June 1999. 